\title{
The role of preoperative axillary ultrasound and fine-needle aspiration cytology in identifying patients with extensive axillary lymph node involvement
}

\author{
Robert Maráz ${ }^{\mathrm{a}}$, Tamás Zombori ${ }^{\mathrm{b}}$, Éva Ambrózay ${ }^{\mathrm{c}}$, \\ Gábor Cserni ${ }^{b, d, *}$ \\ ${ }^{a}$ Department of Surgery, Bács-Kiskun County Teaching Hospital, Nyiri ut 38, H6000 Kecskemét, Hungary \\ ${ }^{\mathrm{b}}$ Department of Pathology, University of Szeged, Allomas u 1, H6720 Szeged, Hungary \\ ${ }^{\mathrm{c}}$ Department of Breast Diagnostics, Mamma Zrt at Kecskemét, Nyiri ut 38, H6000 Kecskemét, Hungary \\ ${ }^{\mathrm{d}}$ Department of Pathology, Bács-Kiskun County Teaching Hospital, Nyiri ut 38, H6000 Kecskemét, Hungary \\ Accepted 4 August 2017 \\ Available online 30 August 2017
}

\begin{abstract}
Introduction: In the recent past, both clinically node-positive and node-negative but sentinel node-positive patients underwent axillary lymph node dissection (ALND), although the two groups seem to have substantially different degree of nodal involvement.

Methods: Data on consecutive primary breast cancer patients with documented axillary ultrasound (AXUS) results who underwent ALND between January 2003 and December 2015 either because of AXUS-guided fine needle aspiration (A-FNAC) results or because of a positive sentinel lymph node were retrospectively analysed.

Results: After exclusions, 316 patients staged by SNB and ALND with negative AXUS or A-FNAC (group A) were compared with 159 patients having positive A-FNAC results (group B). Tumour size and the proportion of mastectomies were greater, histological grade higher and lymphovascular invasion more frequent in Group B, where palpable lymph nodes were also more common. The proportion of cases with extensive nodal involvement (pN2 and pN3 cases) was about 3 times as much in Group B (63\%) than in Group A (18\%). Removal of the 50 patients with palpable lymph nodes from the analysis did not greatly influence these proportions: 60\% and 19\% extensive nodal involvements were noted, respectively. In this series, patients with suspicious AXUS and negative A-FNAC had more often extensive nodal involvement $(25 \%)$ than AXUS negative patients (17\%)

Conclusions: Patients in whom axillary metastases are detected by ultrasound-guided biopsy have significantly more involved nodes than SLNB-positive patients, and therefore are likely to benefit from axillary treatment.

(C) 2017 Elsevier Ltd, BASO The Association for Cancer Surgery, and the European Society of Surgical Oncology. All rights reserved.
\end{abstract}

Keywords: Axillary lymph node dissection; Axillary ultrasound; Breast cancer; Sentinel lymph node biopsy; Tumour burden

\section{Introduction}

Axillary lymph node involvement is one of the most important prognostic factors of breast cancer. Patients without axillary node involvement have a significantly better prognosis than patients with pN1-3 disease [1,2]. Both the total number of nodes retrieved during axillary lymph node dissection (ALND) (positive and negative ones) and

\footnotetext{
* Corresponding author. Department of Pathology, Bács-Kiskun County Teaching Hospital, Nyiri ut 38, H6000 Kecskemét, Hungary.

E-mail addresses: cserni@freemail.hu, csernig@kmk.hu (G. Cserni).
}

the number of metastatic nodes have prognostic importance $[3,4]$. Before the introduction of sentinel lymph node biopsy (SLNB), elective ALND was performed in all patients. By now, SLNB has replaced ALND in the staging of the axilla in clinically node negative breast cancer patients. In patients with a positive sentinel lymph node (SLN), completion ALND had universally been performed until recently. The American College of Surgeons Oncology Group (ACOSOG) Z0011 trial reported equivalent outcomes for SLNB alone compared to completion ALND for women with 1-2 positive sentinel lymph nodes undergoing breast-conserving surgery, whole-breast 
irradiation and systemic therapy [5,6]. In the ACOSOG Z0011 trial, a clinically negative axilla was defined by physical examination only, and it is recognized that axillary palpation can have a relatively high (up to $45 \%$ ) falsenegative rate [7]. Some studies suggest that axillary ultrasound (AXUS) and needle biopsy of abnormal-appearing nodes can appropriately allocate node-positive women to an up-front ALND, avoiding a 2-step axillary procedure $[8,9]$. AXUS guided fine-needle aspiration cytology (AFNAC) of suspicious lymph nodes is recognized as an optimal preoperative procedure for identifying patients with an indication for ALND [10,11]. Clinical nodal staging nowadays often includes palpation, AXUS and AFNAC [12], as neither palpation, nor AXUS alone are considered sufficient to indicate ALND. The present study aimed to reinforce that A-FNAC is a reliable method to a priori select patients with extensive metastatic nodal involvement (defined as having more than 3 metastatic lymph nodes) and distinguish them from those with no or lower nodal load.

\section{Patients and methods}

From a series of 733 consecutive primary invasive breast cancer patients with ALND, those who underwent either A-FNAC and/or SLNB followed by ALND between January 2003 and December 2015 at the Bács-Kiskun County Teaching Hospital were retrospectively analysed. Patients with positive A-FNAC findings were compared to those without preoperative microscopic proof of axillary involvement. In a subset analysis, AXUS-negative cases were also compared to patients with positive AXUS findings but negative A-FNAC results. In the analysis, no attempt was made to exclude patients with palpable axillary lymph nodes due to the reportedly high false-positive rate of this finding even when the axilla seems highly suspicious on physical examination [7,13]. However, subset analyses were performed to see whether or not the main conclusion of the study holds true after the exclusion of patients with a clinically positive axillary status based on palpation alone.

Patients who received neoadjuvant therapies, had distant metastatic disease, recurrent rather than primary disease and those who did not undergo an ALND were excluded.

The preoperative diagnosis of breast cancer was established by mammography, ultrasonography and FNAC or core needle biopsy (CNB) in all patients. Prior to surgery, AXUS was performed routinely as part of the preoperative assessment.

When AXUS was negative, the axillary staging procedure was SLNB, and in case of a positive SLN identified either intraoperatively (by means of imprint cytology) or subsequently during the examination of permanent sections, completion ALND was generally done. In patients with suspicious lymph nodes on AXUS [11,14], A-FNAC was performed. When this yielded a negative result, the patient underwent SLNB. In patients with positive A-FNAC, we performed ALND along with the removal of the tumour by either breast conserving surgery or mastectomy. ALND consisted of the removal of level I and II axillary lymph nodes [15].

Suspicious lymph nodes were defined as nodes that were rounded, had an asymmetrical cortex, thicker than $3 \mathrm{~mm}$ or lost the hyperechoic hilum. Suspicious nodes were aspirated with a 23-gauge needle. Aspirates were either smeared on a slide and fixed in $95 \%$ ethanol, or rinsed, fixed in a $50 \%$ ethanol- $2 \%$ polyethylene glycol solution, and centrifuged, creating a monolayer preparation. Both smears and monolayer slides were Papanicolaou stained.

Our technique of SLNB involved intraparenchymal administration (intra- and/or peritumoral injection in 3-4 depots) of $60-90 \mathrm{MBq} 99 \mathrm{mTc}-$ labelled colloids the day before surgery: either 200-600 nm particle size Sentiscint (Medi-Radiopharma Kft., Érd, Hungary) or 40-80 nm particle size colloids Nanoalbumon (Medi-Radiopharma Kft., Érd, Hungary) or Nanocoll (Gipharma, Saluggia, Italy). From January 2006, we introduced superficial, periareolar injection of the radiocolloid according to the localization of the quadrant harboring the tumour as preferred method. However, in case of non-palpable tumours, the radioactive tracer was injected intraparenchymally, into and around the tumour, with ultrasound (US) guidance to permit Radioguided Occult Lesion Localization (ROLL). Lymphoscintigraphy was generally performed $2 \mathrm{~h}$ after the administration of the radioactive tracer and was often repeated the next day, shortly before surgery, to check whether the highlighted lymph nodes are still there and no further lymph nodes have appeared. Two ml Patent Blue dye was injected intraparenchymally or periareolarly above the tumour after the induction of general anesthesia, 10-15 min before the incision [16].

Staging and the discrimination of metastases, micrometastases and isolated tumour cells (ITC) was done according to the Tumour Node Metastases (TNM) classification of malignant tumours in effect during the study period [17].

Patient and tumour characteristics including age, type of operation, tumour histology, tumour size, presence of vascular invasion, histological grade, oestrogen receptor (ER) and progesterone receptor (PR) status, human epidermal growth factor receptor 2 (HER2)/neu status based on overexpression or amplification were collected along with the outcome measures of the study: axillary nodal status, extra-capsular invasion and the type of axillary metastasis. In the case of multifocal tumours, we took into consideration the size of the largest invasive tumour and the highest grade (if different).

Statistical models for the comparisons included ANOVA on ranks as one-tailed univariate model (Sigmaplot 11.0, Systat Software Inc. San Jose, CA, USA), and logistic regression with backward selection as multivariate model (Stata 9, StataCorp. LLC, College Station, TX, USA). For the subset comparisons $2 \times 2$ contingency tables were used and the chi-square test was used with Yates correction 
for continuity (Vassarstats, [18]) The significance level was set at $\mathrm{p}<0.05$.

\section{Results}

Out of the 733 breast cancer patients with ALND performed, 464 patients underwent SLNB prior to ALND. In contrast, 269 had no SLNB before ALND (Fig. 1).

In the first group of patients we have found no records on AXUS being performed in 139 cases because in the early period examined, this was not routinely recorded. Although these cases were likely to represent AXUSnegative findings, they were excluded because of missing data on AXUS. Nine further cases had to be excluded because ALND had not been performed on the basis of microscopically proven metastases in the SLN: the operating surgeon decided to perform ALND on the basis of intraoperative palpation or the presence of ITCs; imprint cytology was suspicious but not positive in one of these cases and false positive in another. Finally there remained 316 patients staged by SNB and ALND with data on AXUS and A-FNAC if performed, (group A).

In the second group of patients, data on AXUS were missing in 73 cases, and in further 37 cases there was no AXUS performed: so finally 159 patients remained for further analysis (group B) (Fig. 1, Table 1.)

The average tumour size of patients in group A was significantly smaller than that of patients in group B. The proportion of breast conserving surgery was significantly higher for group A patients, justifiable by the larger average tumour size in group B. Invasive ductal carcinoma (no special type carcinoma) was the most common tumour type in both groups of patients. Tumours were less differentiated in group B than in group A $(p<0.001)$. Vascular invasion was significantly more frequent in patients in group $\mathrm{B}$ (Table 1.).

The main aim of our study was to compare the nodal burden in patients with positive A-FNAC and positive SLNB. We found that patients with positive A-FNAC have significantly higher nodal burden (about 3 times as much extensive nodal involvement) compared to SLNB positive patients $(\mathrm{p}<0.001)$. In group $\mathrm{A}, \mathrm{pN} 2$ and $\mathrm{pN} 3$ cases composed $18 \%$ of patients, while in group B we found three times as many of these categories (63\%) (Fig. 2).

Data on axillary staging by palpation were available in all but 15 patients, these were excluded from the subset analysis on physical examination. Altogether 50 patients in the analysis had palpable lymph nodes, $4(1.3 \%)$ in group A and $46(30.1 \%)$ in group B $(\mathrm{p}<0.0001)$. Of the patients who were clinically node negative on palpation, 59/304 (19.4\%) had pN2 or pN3 nodal involvement in Group A, whereas this rate was $64 / 109(60.4 \%)$ in group B $(\mathrm{p}<0.0001)$. Eighty per cent of the pN2 and pN3 breast cancers had no palpable lymph nodes.

Group A patients were divided into two subgroups based on the result of the AXUS. In the first subgroup (A1) there were no suspicious axillary nodes identified,

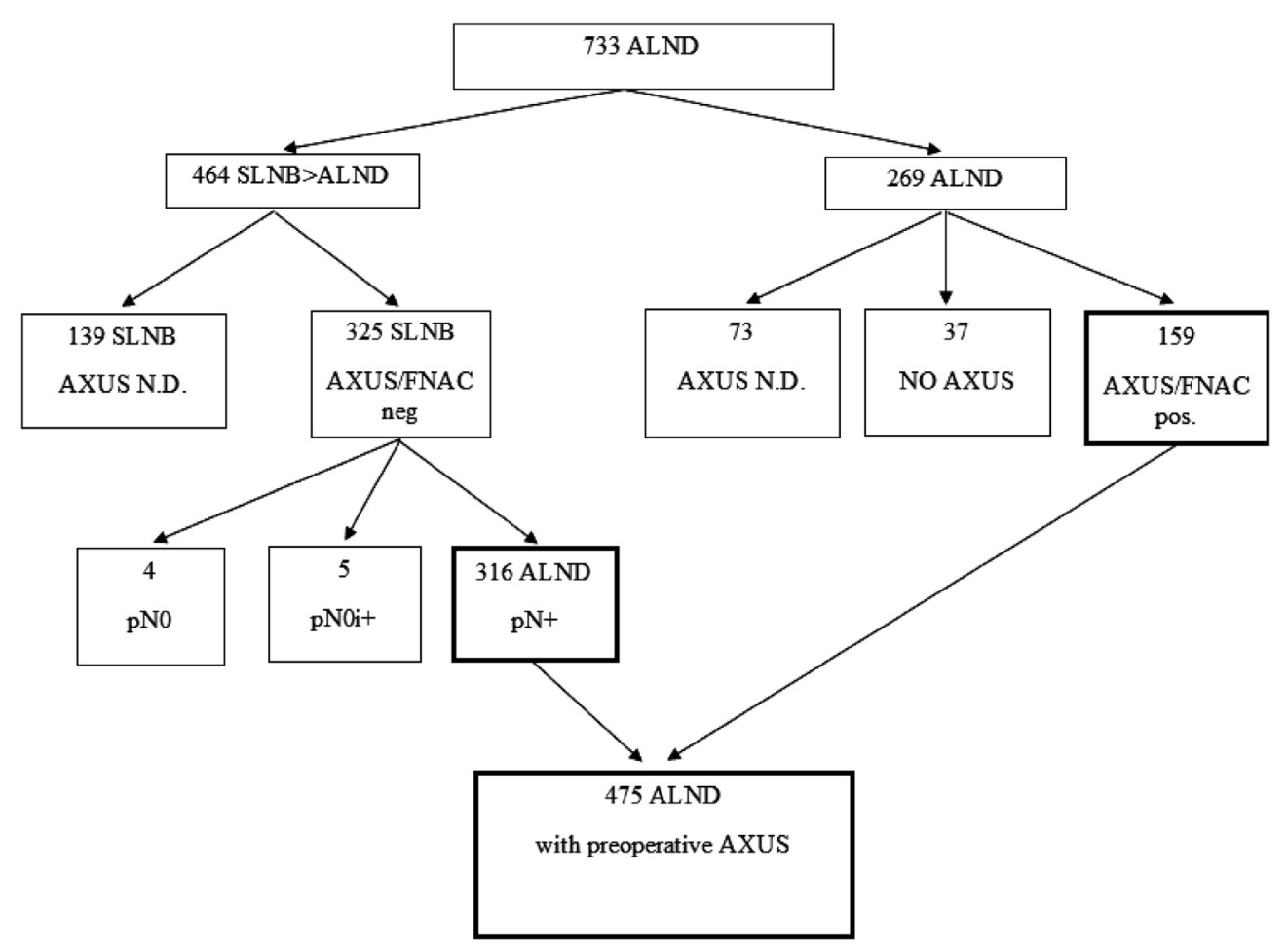

Fig. 1. Case selection details. 
Table 1

Patient demographics and clinico-pathological characteristics in pathologically node-positive Groups A (clinically node-negative staged by SLNB) and B (clinically node-positive staged by ALND).

\begin{tabular}{|c|c|c|c|}
\hline & Group A & Group B & $\mathrm{p}$ value \\
\hline Patients number & 316 & 159 & \\
\hline Average age & 59 & 65 & $<0.001$ \\
\hline Age & & & $<0.001$ \\
\hline$\leq 40$ & 19 & 4 & \\
\hline$\overline{41}-50$ & 64 & 16 & \\
\hline $51-70$ & 177 & 79 & \\
\hline$\geq 71$ & 56 & 60 & \\
\hline Type of operations & & & $<0.001$ \\
\hline BCS & 265 & 85 & \\
\hline Mastectomy & 51 & 74 & \\
\hline Histological type & & & 0.895 \\
\hline IDC & 233 & 119 & \\
\hline ILC & 48 & 22 & \\
\hline Others & 35 & 18 & \\
\hline Tumour size & & & $<0.001$ \\
\hline pT1a-1b & 24 & 5 & \\
\hline pT1c & 166 & 48 & \\
\hline pT2 & 120 & 95 & \\
\hline pT3 & 4 & 11 & \\
\hline pT4 & 2 & 0 & \\
\hline Vascular invasion & & & $\mathbf{0 . 0 3 7}$ \\
\hline Absent & 185 & 77 & \\
\hline Present & 131 & 82 & \\
\hline Histological grade & & & $<0.001$ \\
\hline 1 & 65 & 17 & \\
\hline 2 & 133 & 48 & \\
\hline 3 & 118 & 94 & \\
\hline Receptor status $/^{\mathrm{a}}$ & & & $<0.001$ \\
\hline $\mathrm{ER}+$ & 277 & 118 & $<0.001$ \\
\hline $\mathrm{ER}-$ & 39 & 41 & \\
\hline $\mathrm{PR}+$ & 245 & 106 & 0.011 \\
\hline $\mathrm{PR}-$ & 68 & 51 & \\
\hline HER2 + & 27 & 22 & $\mathbf{0 . 0 5 0}$ \\
\hline HER2- & 289 & 136 & \\
\hline \multicolumn{4}{|l|}{ Outcome measures } \\
\hline Axillary nodal status & & & $<0.001$ \\
\hline $\mathrm{pN} 1$ & 258 & 59 & \\
\hline $\mathrm{pN} 2$ & 44 & 48 & \\
\hline $\mathrm{pN} 3$ & 14 & 52 & \\
\hline $\mathrm{EC}^{\mathrm{c}}$ & & & 0.008 \\
\hline $\mathrm{EC}+$ & 156 & 99 & \\
\hline EC- & 159 & 60 & \\
\hline MIC & 69 & 2 & $<0.001$ \\
\hline MAC & 247 & 157 & $<0.001$ \\
\hline $\begin{array}{l}\text { Total number of nodes } \\
\text { excised (mean) }\end{array}$ & 13.7 & 15.1 & 0.015 \\
\hline
\end{tabular}

Significant values are highlighted in bold.

ALND: axillary lymph node dissection, BCS: breast conserving surgery, EC: extracapsular spread, ER: oestrogen receptor, HER2: human epidermal growth factor receptor 2, IDC: invasive ductal carcinoma (no special type breast carcinoma), ILC: invasive lobular carcinoma, PR: progesterone receptor, MAC: macrometastasis, MIC: micrometastasis, SLNB: sentinel lymph node biopsy.

${ }^{\text {a }}$ PR status was unknown in 3 cases from Group A and 2 cases from Group B and these cases were not considered in the statistics.

b HER-2 status was unknown in 1 case from Group B and this case was not considered in the statistics.

c Extracapsular spread was not assessable in 1 case from Group A, and this case was therefore omitted from the statistics. therefore no FNAC was performed, while in the second subgroup (A2), FNAC was necessary. In the two subgroups, we analysed the axillary nodal status, extracapsular invasion, the type of axillary metastasis and the average size of the maximal diameter of the SLN metastasis. In a few cases, a lymph node metastasis was found in a non-radioactive and non-blue lymph node removed during SLNB, i.e. a non-SLN (NSLN) by restrictive definition; from a pragmatic approach, these were recorded within the SLN metastasis group according to a more allowing definition [19].

Patients in subgroup A2 (where A-FNAC was performed) had significantly higher nodal burden, and the rate of $\mathrm{pN} 1$ patients was significantly lower (75\%) compared to patients in subgroup A1 without FNAC (83\%) (Table 2) (Fig. 3). The other measures of nodal involvement (i.e. rate of micrometastasis versus macrometastasis, mean largest size of the SLN metastasis, rate of extracapsular extension) showed no significant differences between the two subgroups.

\section{Discussion}

The presence of axillary metastasis is one of the most important prognostic factors in breast cancer $[1,2,20]$, however it is important to remember that more than $60 \%$ of all primary operable breast cancers do not have axillary lymph node metastasis [21]. The diagnostic role of preoperative AXUS and FNAC has increased significantly [22], as physical examination has been recognized to have a relatively high false-negative and false-positive rate $[7,12]$. Patients with no suspicious nodes on ultrasound imaging and those with a negative ultrasound-guided biopsy might even be spared the SLNB procedure. Several randomized clinical trials (SOUND, INSEMA, NCT 01821768 and BOGG 2013-08) were initiated to clarify this scenario by randomizing early breast cancer patients between SLNB and no SLNB after negative AXUS/FNAC [23-26]. These studies demonstrated the need to clarify the role of A-FNAC in detecting extensive nodal involvement, too.

Our study shows that patients with a positive A-FNAC have a substantially higher nodal tumour burden than those with a positive SLNB. Patients in the A-FNAC group were also statistically more likely to undergo a mastectomy, to have a higher tumour grade and extranodal extension. This group was found to have higher numbers of ERnegative and HER2-positive tumours. These results are similar to those found in other studies [27,28]. The metaanalysis by van Wely et al. [29] shows that $56 \%$ of the patients with positive A-FNAC have three or more positive ALNs, and the other big study by G.M. Kramer et al. [30] shows almost identical numbers, with a positive predictive value (PPV) of 58\%. These patients could probably benefit from additional axillary treatment. 


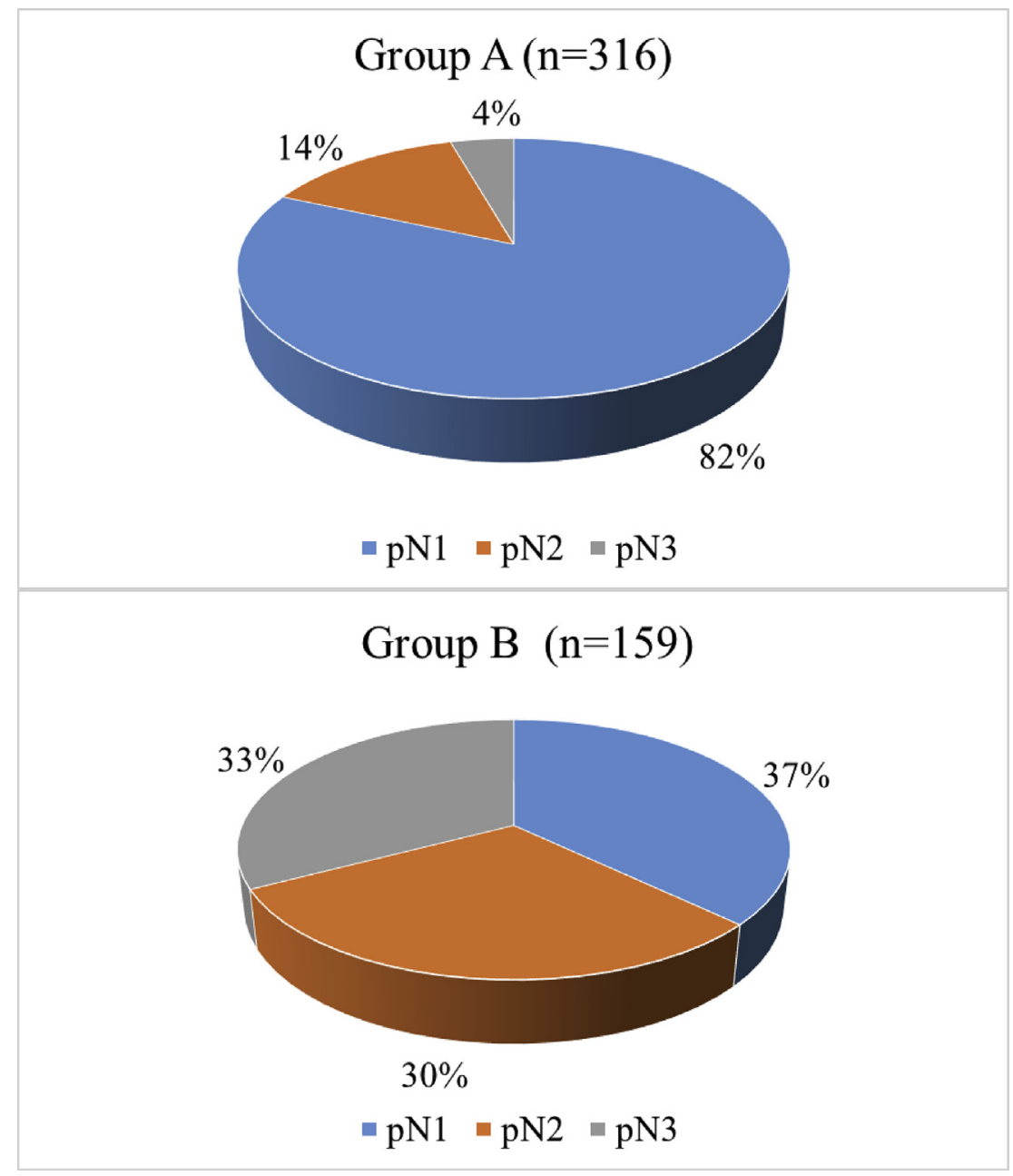

Fig. 2. Nodal involvement according to pTNM categories in Groups A and B.

Table 2

Comparison of the clinically node-negative patients undergoing SLNB and ALND according to the AXUS findings.

\begin{tabular}{lll}
\hline & $\begin{array}{l}\text { A1: No suspicion on AXUS, } \\
\text { therefore no FNAC }\end{array}$ & $\begin{array}{l}\text { A2: Suspicion on AXUS, } \\
\text { therefore FNAC performed, but } \\
\text { negative for metastasis }\end{array}$ \\
\hline Patients number & 272 & 44 \\
pN1 & 225 & 33 \\
pN2 & 39 & 5 \\
pN3 & 8 & 6 \\
EC & 132 & 24 \\
EC+ & 139 & 20 \\
EC- & 61 & 8 \\
MIC & 211 & 36 \\
MAC & 6.2 & 7.83 \\
Mean maximum size of SLN & & \\
$\quad$ metastasis (mm) & & 0.011 \\
\hline
\end{tabular}

Significant values are highlighted in bold.

ALND: axillary lymph node dissection, AXUS: axillary ultrasound, EC: extra capsular spread, FNAC: fine needle aspiration cytology, MAC: macrometastasis, MIC: micrometastasis, mm: millimeter, SLN: sentinel lymph node, SLNB: sentinel lymph node biopsy.

${ }^{\text {a }}$ Extracapsular spread was not assessable in 1 case from Group A1, and was therefore omitted from the statistics. 


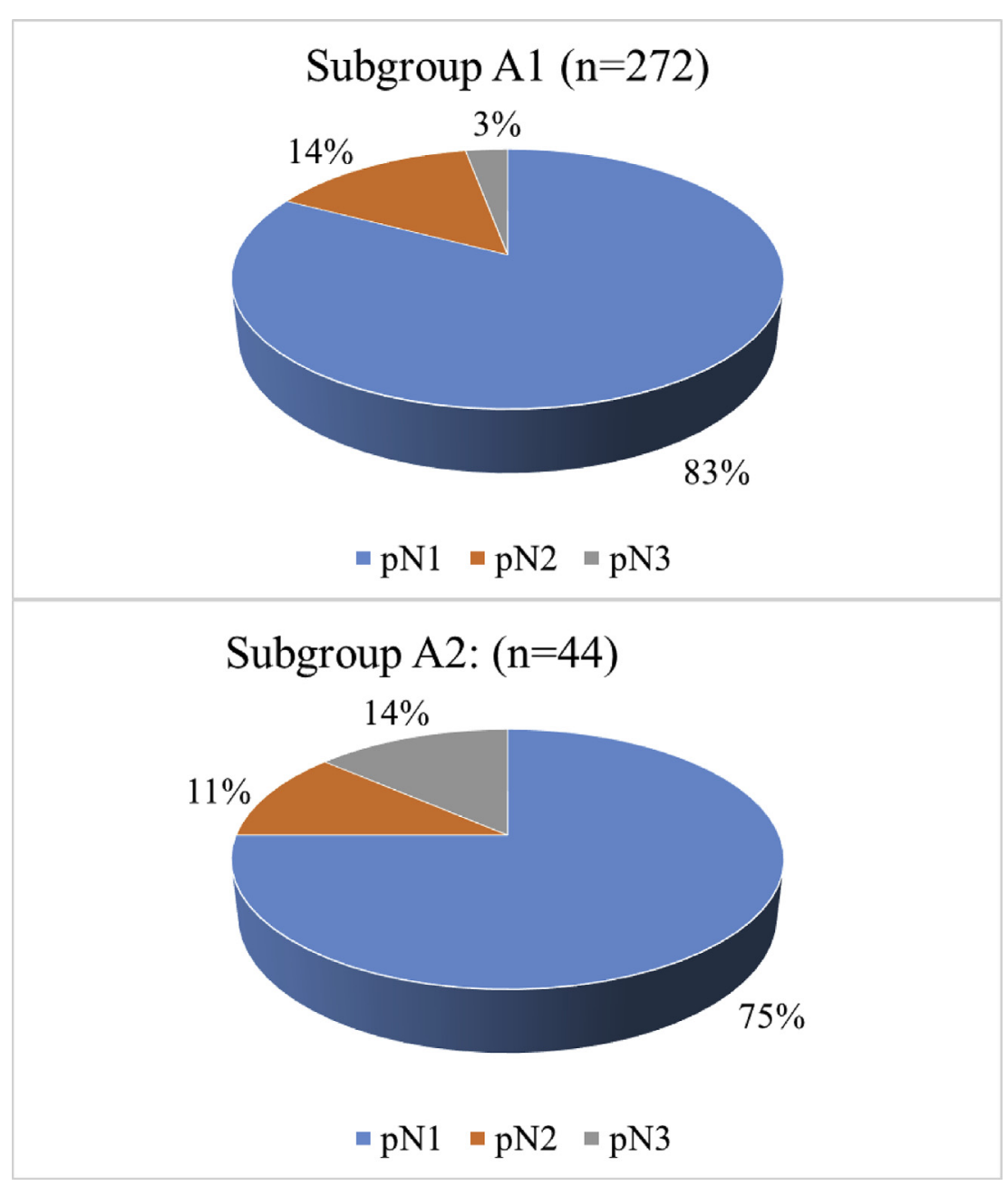

Fig. 3. Nodal involvement according to pTNM categories in Subgroups A1 and A2.

The recent meta-analysis found no difference in nodal burden between those who had suspicious axillary ultrasound findings but a negative A-FNAC and those who had an initial negative AXUS [29]. In contrast, we have found a significant difference between these groups in terms of nodal burden $(p=0.017)$, (Table 2). This may be due to the small case numbers, but can also be related to false-negative A-FNAC results. AXUS alone seems to be of relatively high (83\%) specificity and $71 \%$ sensitivity in identifying the group of patients with $\geq 3$ lymph nodes involved [31,32], but A-FNAC may still miss some of these cases. Indeed, AXUS-guided core biopsies were found to have a higher positive predictive value and sensitivity than A-FNAC in identifying axillary lymph node metastases preoperatively [33]. At present, both patients with a negative AXUS findings, and those with suspicious AXUS findings but negative A-FNAC should be considered clinically node negative, and most will have low nodal burden (pN1 disease) in the axilla: $83 \%$ and $75 \%$, respectively on the basis of our data; although these rates are statistically different, this difference may be of limited clinical importance.

Our results, in keeping with previous studies demonstrate that clinically node positive breast cancer patients are different from clinically node negative and pathologically node positive patients.

\section{Conclusions}

Although clinically node-negative breast cancer patients with SLNB proven lymph node involvement of the axilla and those (clinically node-positive) with A-FNAC proven nodal involvement are both node-positive, they differ significantly in terms of nodal tumour burden. Patients in whom axillary metastases are detected by ultrasound-guided biopsy have significantly more involved nodes than SLNBpositive patients, and therefore are expected to have a worse prognosis; it is believed that they are more likely to benefit from further axillary treatment than patients with no preoperative biopsy proven evidence of nodal involvement. 


\section{Acknowledgment}

The authors thank the help of further members of the multidisciplinary breast team, Drs Katalin Lóránd, Orsolya Serföző, Rozália Hajnal-Papp and Péter Serényi for their diagnostic contribution, and József Papp-Szekeres and László Sikorszki for their support of the team work. Special thanks are due to Tibor Nyári (Department of Informatics, University of Szeged) for his help in the statistical analysis of our data. This work was supported by the National Research, Development and Innovation Office [grant number: GINOP-2.3.2-15-2016-00020].

\section{References}

[1] Carter CL, Allen C, Henson DE. Relation of tumor size, lymph node status, and survival in 24740 breast cancer cases. Cancer 1989;63:181-7.

[2] Nemoto T, Vana J, Bedwani RN, Baker HW, McGregr FH, Murphy GP. Management and survival of female breast cancer: results of a national survey by the American College of Surgeons. Cancer 1980;45:2917-24.

[3] Vinh-Hung V, Verschraegen C, Promish DI, Cserni G, Van de Steene J, Tai P, et al. Ratios of involved nodes in early breast cancer. Breast Cancer Res 2004;6:680-8.

[4] Vinh Hung V, Nguyen NP, Cserni G, Truong P, Woodward W, Verkooijen HM, et al. Prognostic value of nodal ratios in node-positive breast cancer: a compiled update. Future Oncol 2009;5:1585-603.

[5] Giuliano AE, McCall L, Beitsch P, Whitworth PW, Blumencranz P, Leitch AM, et al. Locoregional recurrence after sentinel lymph node dissection with or without axillary dissection in patients with sentinel lymph node metastases: the American College of Surgeons Oncology Group Z0011 randomized trial. Ann Surg 2010;252:426-32.

[6] Giuliano AE, Ballman K, McCall L, Beitsch P, Whitworth PW, Blumencranz $\mathrm{P}$, et al. Locoregional recurrence after sentinel lymph node dissection with or without axillary dissection in patients with sentinel lymph node metastases: long-term follow-up from the American College of Surgeons Oncology Group (Alliance) ACOSOG Z0011 randomized trial. Ann Surg 2016;264:413-20.

[7] Sacre RA. Clinical evaluation of axillar lymph nodes compared to surgical and pathological findings. Eur J Surg Oncol 1986;12:169-73.

[8] Rao R, Euhus D, Mayo HG, Balch C. Axillary node interventions in breast cancer: a systematic review. JAMA 2013;310:1385-94.

[9] Shah-Khan M, Boughey JC. Evolution of axillary nodal staging in breast cancer: clinical implications of the ACOSOG Z0011 trial. Cancer Control 2012;19:267-76.

[10] Deurloo EE, Tanis PJ, Gilhuijs KG, Muller SH, Kröger R, Peterse JL, et al. Reduction in the number of sentinel lymph node procedures by preoperative ultrasonography of the axilla in breast cancer. Eur J Cancer 2003;39:1068-73.

[11] Sapino A, Cassoni P, Zanon E, Fraire F, Croce S, Coluccia C, et al. Ultrasonographically-guided fine-needle aspiration of axillary lymph nodes: role in breast cancer management. Br J Cancer 2003;88:702-6.

[12] Hortobagyi G, Connolly JL, D’Orsi CJ, Edge SB, Mittendorf EA, Rugo HS, et al. Breast. In: Amin MB, Edge SB, Greene FL, Byrd DR, Brookland RK, Washington MK, et al., editors. AJCC Cancer staging manual. 8th ed. New York: Springer; 2017. p. 587-628.

[13] Specht MC, Fey JV, Borgen PI, Cody HS 3rd. Is the clinically positive axilla in breast cancer really a contraindication to sentinel lymph node biopsy? J Am Coll Surg 2005;200:10-4.

[14] Ambrózay E, Cserni G, Serényi P, Lőrincz M, Loránd K. The role of axillary nodal staging during preoperative breast diagnostics. Eur J Cancer Suppl 2004;2:92-3.
[15] Cady B. Total mastectomy and partial axillary dissection. Surg Clin North Am 1973;53:313-8.

[16] Cserni G, Rajtár M, Boross G, Sinkó M, Svébis M, Baltás B. Comparison of vital dye-guided lymphatic mapping and dye plus gamma probe-guided sentinel node biopsy in breast cancer. World J Surg 2002;26:592-7.

[17] Edge SB, Byrd DR, Compton CC, Fritz AG, Greene FL, Trotti A, editors. AJCC cancer staging manual. 7th ed. New York: Springer; 2010.

[18] Lowry, R. http://vassarstats.net. [Accessed 30 July 2017].

[19] Carmon M, Olsha O, Rivkin L, Spira RM, Golomb E. Intraoperative palpation for clinically suspicious axillary sentinel lymph nodes reduces the false-negative rate of sentinel lymph node biopsy in breast cancer. Breast J 2006;12:199-201.

[20] Clarke K, Collins R, Darby S, Davies C, Elphinstone P, Evans V, et al. Effects of radiotherapy and of differences in the extent of surgery for early breast cancer on local recurrence and 15-year survival: an overview of the randomised trials. Lancet 2005:2087-106.

[21] Gerber B, Heintze K, Stubert J, Dietrich M, Hartmann S, Stachs A, et al. Axillary lymph node dissection in early-stage invasive breast cancer: is it still standard today? Breast Cancer Res Treat 2011; 128:613-24.

[22] Cools-Lartigue J, Meterissian S. Accuracy of axillary ultrasound in the diagnosis of nodal metastasis in invasive breast cancer: a review. World J Surg 2012;36:46-54.

[23] Gentilini O, Veronesi U. Abandoning sentinel lymph node biopsy in early breast cancer? A new trial in progress at the European Institute of Oncology of Milan (SOUND: sentinel node vs Observation after axillary UltraSouND). Breast 2012;21:678-81.

[24] Reimer T, Hartmann S, Stachs A, Gerber B. Local treatment of the axilla in early breast cancer: concepts from the national surgical adjuvant breast and bowel project B-04 to the planned intergroup sentinel mamma trial. Breast Care 2014;9:87-95.

[25] Cyr, A. A prospective randomized trial of sentinel lymph node biopsy versus no additional staging in patients with clinical T1-T2 N0 M0 invasive breast cancer and negative axillary ultrasound. https://clinicaltrials.gov/ct2/show/NCT01821768. [Accessed 25 June 2017].

[26] Smidt, ML. Clinically node negative breast cancer patients undergoing breast conserving therapy: sentinel lymph node procedure versus follow up. https://www.boogstudycenter.nl/studie/273/2013-08lumpectomie.html. [Accessed 25 June 2017].

[27] Boland MR, Ni Cearbhaill R, Fitzpatrick K, Walsh SM, Evoy D, Geraghty J, et al. A positive node on ultrasound-guided fine needle aspiration predicts higher nodal burden than a positive sentinel lymph node biopsy in breast carcinoma. World J Surg 2016;40: 2157-62.

[28] Castellano I, Deambrogio C, Muscara F, Chiusa L, Mariscotti G, Bussone R, et al. Efficiency of a preoperative axillary ultrasound and fine-needle aspiration cytology to detect patients with extensive axillary lymph node involvement. PLoS One 2014;9, e106640.

[29] van Wely BJ, de Wilt JHW, Francissen C, Teerenstra S, Strobbe LJA. Meta-analysis of ultrasound-guided biopsy of suspicious axillary lymph nodes in the selection of patients with extensive axillary tumour burden in breast cancer. Br J Surg 2015;102: 159-68.

[30] Kramer GM, Leenders MW, Schijf LJ, Go HL, van der Ploeg T, van den Tol MP, et al. Is ultrasound-guided fine-needle aspiration cytology of adequate value in detecting breast cancer patients with three or more positive axillary lymph nodes? Breast Cancer Res Treat 2016;156:271-8.

[31] Jackson RS, Mylander C, Rosman M, Andrade R, Sawyer K, Sanders T, et al. Normal axillary ultrasound excludes heavy nodal disease burden in patients with breast cancer. Ann Surg Oncol 2015;22:3289-95. 
[32] Abe H, Schacht D, Sennett CA, Newstead GM, Schmidt RA. Utility of preoperative ultrasound for predicting $\mathrm{pN} 2$ or higher stage axillary lymph node involvement in patients with newly diagnosed breast cancer. AJR Am J Roentgenol 2013;200:696-702.
[33] Vidya R, Iqbal FM, Bickley B. Pre-operative axillary staging: should core biopsy be preferred to fine needle aspiration cytology? Ecancermedicalscience 2017;11:724. http://dx.doi.org/10.3332/ecancer.2017. 724. 